\title{
Does a Difference Between Volunteers and Other People's Focus an Self-Development Targeting Exist?
}

\author{
Lucie Zarubova \\ Faculty of Economics \\ University of West Bohemia \\ Pilsen, Czech Republic \\ zarubovl@kpm.zcu.cz
}

\author{
Lenka Svecova \\ MIAS School of Business \\ Czech Technical University in Prague \\ Prague, Czech Republic \\ lenka.svecova@cvut.cz
}

\begin{abstract}
The paper deals with the topic of volunteering in the Czech Republic. The motivation of volunteers consists of several motivators that are individually different. The volunteer is not financially rewarded for their work, so it is important to know their volunteering initiative. Is volunteering linked to preparation for self-development? The result of the questionnaire survey is the answer, whether there is a relationship between volunteers and people who do not want to be volunteers focused on self-development and organization of their self-development. The result of the survey brings benefits for managers. The result can help them to better understand the needs of volunteers that they can use to manage them successfully. The survey was considered at a certain time without repetition. The limitation is that respondents respond their views, but they do not talk about actual practices and that could be differ.
\end{abstract}

Keywords: volunteer, self-development, formal volunteering

\section{INTRODUCTION}

Volunteers sacrifice time and energy for others. They can't take money for their voluntary job. It is important to stimulate volunteers to support their internal motivation for voluntary work [1].

Management of volunteers help to volunteers to stay longer time satisfied with their voluntary job. The research is focused on formal volunteering which is organized. The organized work is called "the volunteer management". The management helps to participate volunteers to volunteer projects. The management is important for evaluation of their job to develop their skills and knowledge. Manager of volunteers are basically called coordinator [2].

The article answers the question: "Have people who would like to be a volunteer have different approach to the self-development than people who would not like to be?" The results described are based on primary research, which was conducted in the form of a questionnaire survey follow.

\section{LITERATURE REVIEW}

\section{A. Motivation of Volunteers}

Motivation is defined as an inner motive that make a direction and power for our behaviour and action to carry out our targets [3]. The internal motivation is the process that a person comes to the value of activities, evaluates them by making the activity itself a part of it [4]. Volunteers competences support motivation to self-development [5]; [6]. The internal and the external motivation also collaborate with personal targets that are connected with individual's preferences.

The Theory of Needs by Abraham Maslow [7] divides the level of human needs into five groups: Physiological needs; Safety needs; Needs of social belonging; Needs of self-esteem; The need for self-actualization. Selfactualization or Self-development includes the desire to become more fully self-abilities, to be anything according to his ability. These groups discuss Suyono \& Mudjanarko [8] and Frankl [9]. The gratification of lower needs is a prerequisite for work on higher needs (self-actualization, self-esteem). Volunteers are motivated by using their talents for the creativity and to use their potential (self-actualization, self-development, transcendence) [10]; [11]. Motivation is an internal incentive to start one's own activities and to initiate a willingness and organism to act which is need for selfdevelopment and volunteering. The management of volunteers needs to distinguish individual motivation of each volunteer for better leading them [1].

\section{B. Volunteering - Way of Self-development}

Volunteer can become a volunteer in the Czech Republic according to Act No. 198/2002 Coll., On volunteer service, § 3 , par. 1. Volunteer is a person who is older than 15 years for volunteering in the Czech Republic and older than 18 years for volunteering abroad. Volunteering, or voluntarism, is offering one's time to a voluntary work without financial payment. Volunteering is divided into formal and informal groups. Advocacy, community welfare, religious activities, environmental awareness and remediation, animal welfare, special needs assistance, adult education, political causes, and fundraising are examples of volunteering work [12]. Volunteers join for different reasons, notably altruism and personal relevance. They value staff relationships, health gains, new knowledge, and compensation, and expect professionalism and good organization [13].

Work experiences are valuable commodity that those seeking entry to an occupation may be willing to work without pay in order to acquire it [14]. Volunteering to support new career (or change) can be understood as a response to the risks posed by complex social, political and economic circumstances. The volunteering is an opportunity to develop own education and other skills. It has been found that education, which leads to the development of people in conceptual and procedural knowledge, is mostly based on practices not related to so-called spreadsheet education. Gerdeman et al. [15] and Thompson \& Russell [16] discuss a theme relating to the interaction between the professional development of trainees and volunteer status, including 
vulnerability, participation in professional activities, and the transition to paid employment. Volunteering is associated with higher levels of support than paid work, providing an important motivation for becoming or remaining a volunteer trainee. Education changes may be seen as a product of broader societal changes, governments seek to reduce state commitments by individualising social risk and transferring the costs of other education to its recipients [17]; [18]; [19]; [20]. Own personal changes of self-development are push of a market like mirror of market behaviour for entrepreneur [17]; [21].

People can improve in areas like scientific rationale [22], and critical thinking skills [23], communication [24]. One of the functions of education is repeating knowledge to translate it into practice to transform knowledge. [25]. Involvement of people in the field will help them to gain information about how organizations work, how theoretical knowledge is used in practice. Initial motivation of a volunteer plays an important role in the process and outcomes of learning, lessons and training. Low personal engagement can be critical to the effectiveness of education and the future performance of any worker. Higher personal engagement can convince perseverance, personal awareness and other qualities for future employment. Self-development is conditioned by a certain degree of self-reflection that ensures that the individual is aware that they can control their personal development [26]; [27]; [28]; [29]; [30].

\section{Self-reflection}

Self-reflection is one of tool for self-development. Selfreflection is a common component of many programs for volunteers, particularly as a means of identifying any potential barriers to communicating [31]; [32]. Reflection include the intellectual and affective self-development activities that individuals engage in to explore people experiences and process knowledge from the life, leading to new awareness of themselves or understanding. Reflection can be considered like addressing any personal discomfort or emotion that may be rooted in experience, inexperience, beliefs or culture. Reflection is a method of reviewing past experiences, both personal and professional, examining their impact and outcomes, then applying these new insights or learning to future practice.

Sandars [33] states that without level of guidance and challenge reflection may limit the opportunity for students to develop and expand their learning. In support, Ghaye [34] suggests that effective reflection should be organised from manager of volunteering and structured and triggered by a question which demands the participant to look critically at their actions and question their efficacy [35].

Respondents were forced to take a self-reflective look at the questions and assess whether they were more comfortable with organized self-development management or rather a level of relaxation associated with entertainment, without having to address their own development.

\section{OWN RESEARCH - SELF-DEVELOPMENT}

A total of 154 questionnaires on this article were completed. The respondents are high school and university students who are preparing for their working life. The questionnaire was composed of several questions that are focused on management areas and preferences of respondents.
The hypothesis was formulated: "People who would like to be a volunteer have different approach to the selfdevelopment than people who would not like to be." Respondents answered questions whether they want to be a volunteer or not and whether they were or weren't volunteer before. Group of respondents count: People who were and would like to be a volunteer again (68); People who were and wouldn't like to be a volunteer again (21); People who weren't and wouldn't like to be a volunteer (28); People who weren't and wouldn't like to be a volunteer (37). The groups are normalized for a possible comparison. The answers to the questions were scaled. Scales were grouped into positive and negative groups. Statements that respondents evaluate are:

- Volunteers are motivated only by helping others.

- Every person can be enthusiastic about their work if they choose it according to their personal preferences.

- If I perform a difficult task when people around me try to succeed together, I succeed.

- I build my career according to my personal development plan.

- If I am a volunteer, my condition is to discuss the development plan with the coordinator.

- I will volunteer when I see the immediate output of my work.

- I will volunteer if I have a milestone plan.

- I will volunteer without a set plan.

- What I want to do as a volunteer are my hobbies.

- I expect some benefit for myself from the volunteer project.

- I want to receive feedback from the people I work with.

The hypothesis was formulated: "People who would like to be a volunteer have different approach to the selfdevelopment than people who would not like to be."

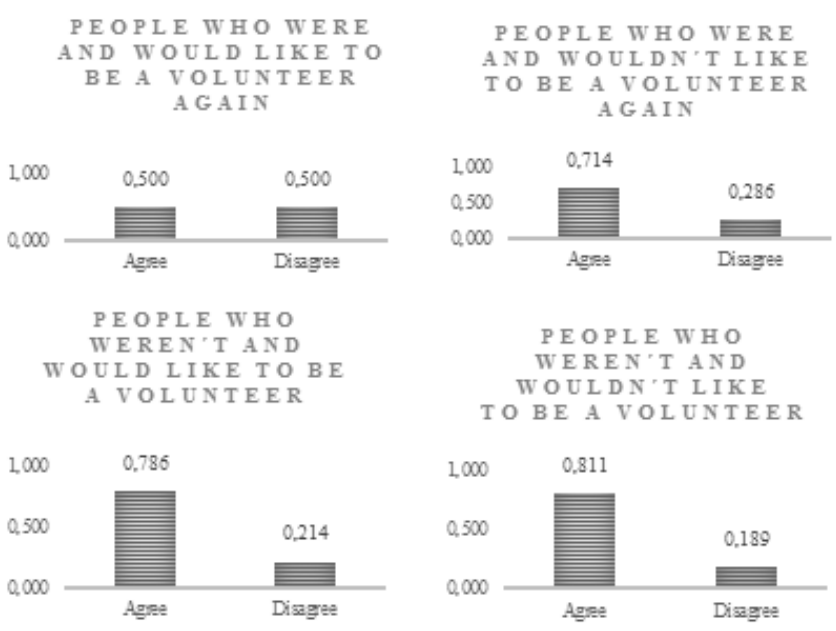

Fig. 1. Volunteers are motivated only by helping to others

Fig. 1 shows percentage answer of respondents who agree or disagree with the sentence: Volunteers are motivated only by helping to others. People who were and would like to be a volunteer again answered same count of agree or disagree. The respondents who answered disagree in 
this group can be acquainted with their self-development in the process of volunteering. The same mentions can be in other group of respondents but there are more positive agree points. Fig. 1 is the author research.

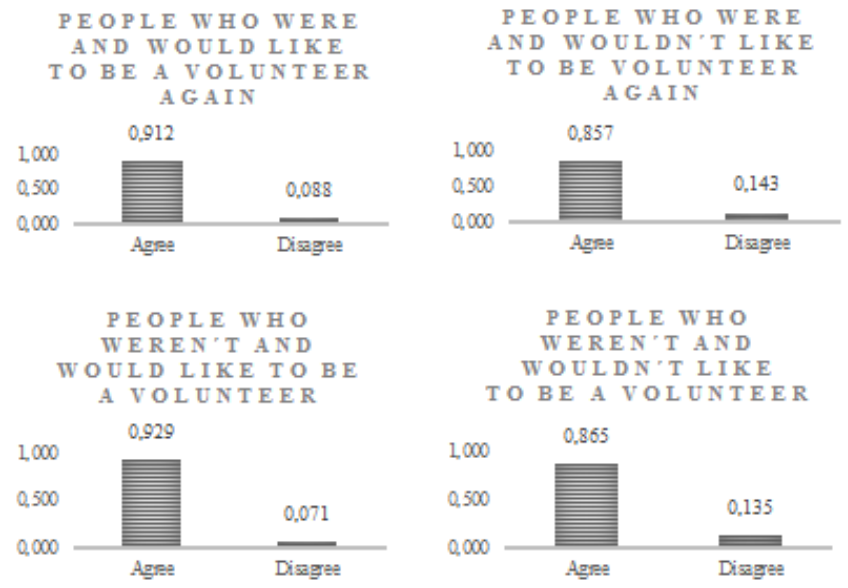

Fig. 2. Every person can be enthusiastic about their work if they choose it according to their personal preferences

Fig. 2 shows percentage answer of respondents who agree or disagree with the sentence: Every person can be enthusiastic about their work if they choose it according to their personal preferences. Whole groups answered simultaneously, cause of it could be a conviction that people know what they want. Fig. 2 is the author research.
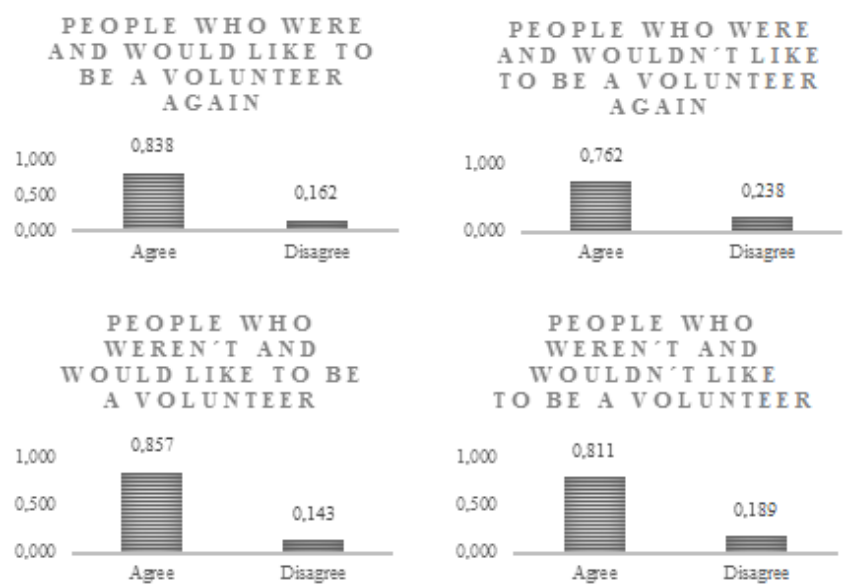

Fig. 3. If I perform a difficult task when people around me try to succeed together, I succeed

Fig. 3 shows percentage answer of respondents who agree or disagree with the sentence: If I perform a difficult task when people around me try to succeed together, I succeed. Whole groups answered simultaneously. The topic being compared is general, this is not in full contact with volunteering, it is thinking about a leadership and respondents' role in it. Fig. 3 is the author research.
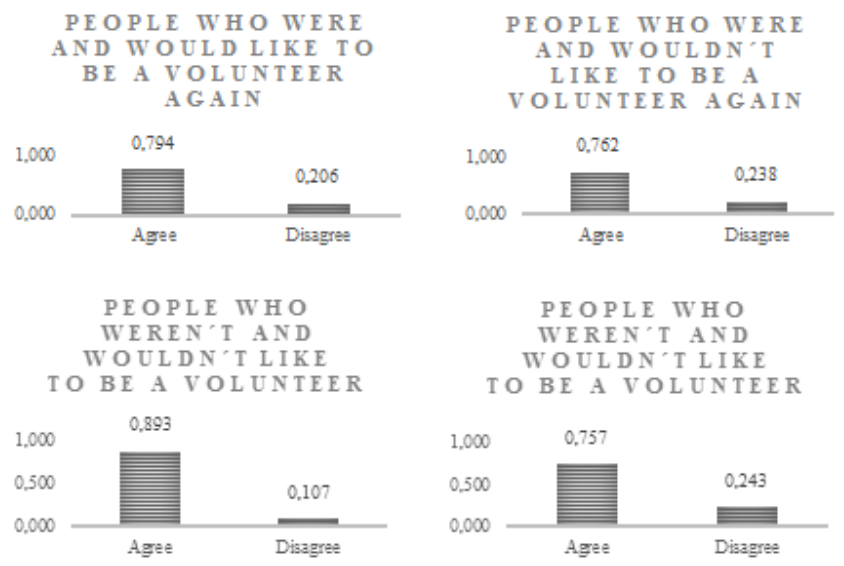

Fig. 4. I build my career according to my personal development plan

Fig. 4 shows percentage answer of respondents who agree or disagree with the sentence: I build my career according to my personal development plan. Whole groups answered simultaneously again. The topic being compared is general, this is not in full contact with volunteering like in the sentence before in Fig. 3. Fig. 4 is the author research.
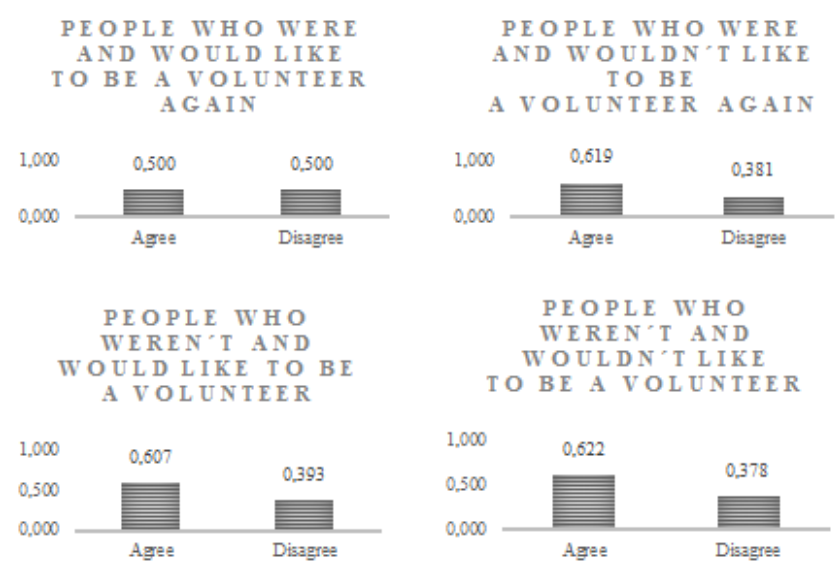

PEOPLE WHO

WEREN'T AND

WOULDN'T LIKE

TOBEA VOLUNTEER

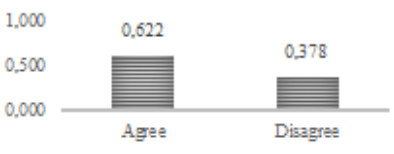

Fig. 5. If I am a volunteer, my condition is to discuss the development plan with the coordinator

Fig. 5 shows percentage answer of respondents who agree or disagree with the sentence: If I am a volunteer, my condition is to discuss the development plan with the coordinator. There are little differences. People who were and would like to be a volunteer again has 50-percentage compliance. The other groups have similar variance of answer. Cause could be that respondents enter into volunteer projects through a contract according to set conditions. They choose the project in connection with the personal preferences that could comprise them self-development in some area of knowledge, skills, etc. Fig. 5. is the author research. 

AND WOULDN'T LIKF

PEOPLE WHO WERE AND WOULD LIKE TO

BE A VOLUNTEER A G A I N

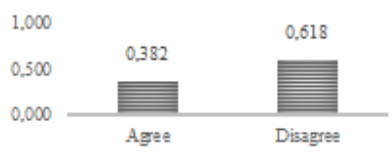
WEREN'T AND WOULD LIKE TO BE

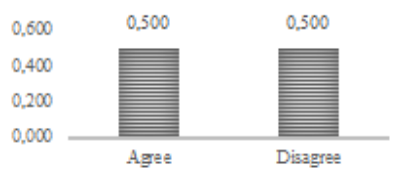
WEREN'T AND WOULDN'T LIKE TO BE A VOLUNTEER
PEOPLE WHO WERE A VOLUNTEER

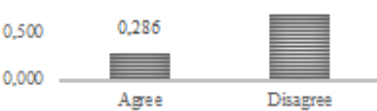

PEOPLE WHO

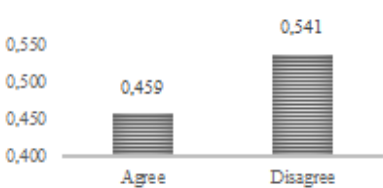

Fig. 6. I will volunteer when I see the immediate output of my work

Fig. 6 shows percentage answer of respondents who agree or disagree with the sentence: I will volunteer when I see the immediate output of my work. There are more disagree answers. Volunteers are predominantly like one point of a larger colossus. Some focus of volunteering does not allow seeing the outcome of volunteering by its very nature, such as the care of the dying or other services, etc. In these cases, these outputs take place more inside of the people than outside it is impossible to see it. Fig. 6. is the author research.
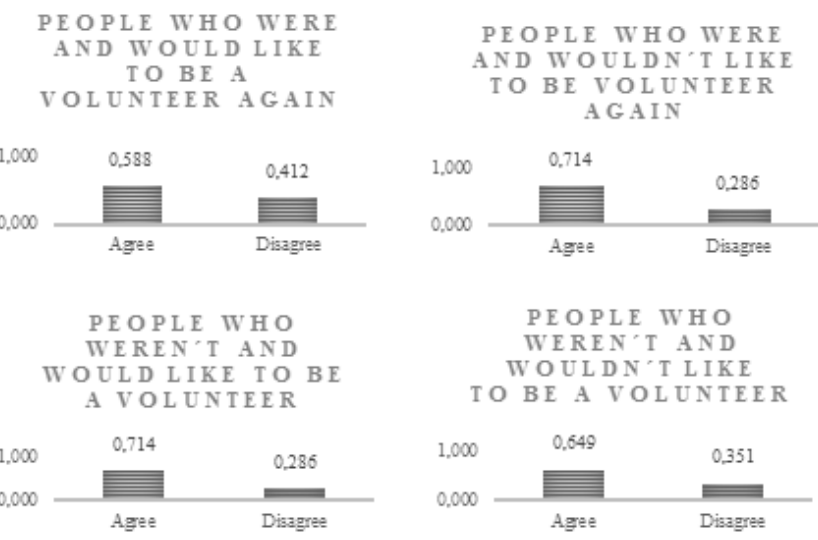

Fig. 7. I will volunteer if I have a milestone plan

Fig. 7 shows percentage answer of respondents who agree or disagree with the sentence: I will volunteer if I have a milestone plan. Whole groups have more positive answers. The group where respondents have the most of experiences with the volunteering and they want to do it in future again have more balanced answer. The cause could be that there is not specific long term or short-term volunteering projects. The affirmation mention that the general preference of respondents to have it. Fig. 7. is the author research.
PEOPLE WHO WERE AND WOULD LIKE TO BEA VOLUNTEER A G A I N

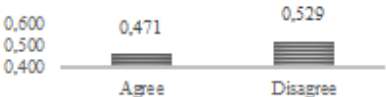
PEOPLE WHO WERE TO BE A VOLUNTEER A G A I N

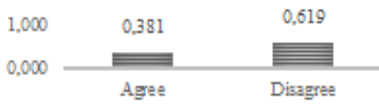

PEOPLE WHO

WEREN'T AND

PEOPLE WHO

WEREN'T AND

WOULD LIKE TO BE

A VOLUNTEER

WOULDN'T LIKE

TOBEA VOLUNTEER
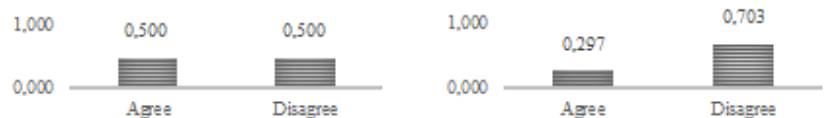

Fig. 8. I will volunteer without a set plan

Fig. 8 shows percentage answer of respondents who agree or disagree with the sentence: I will volunteer without a set plan. There is possible to see differences in preferences. Volunteering contracts contain pre-defined conditions for volunteering which are predominantly concluded in formal volunteering (organized). Fig. 8 is the author research.
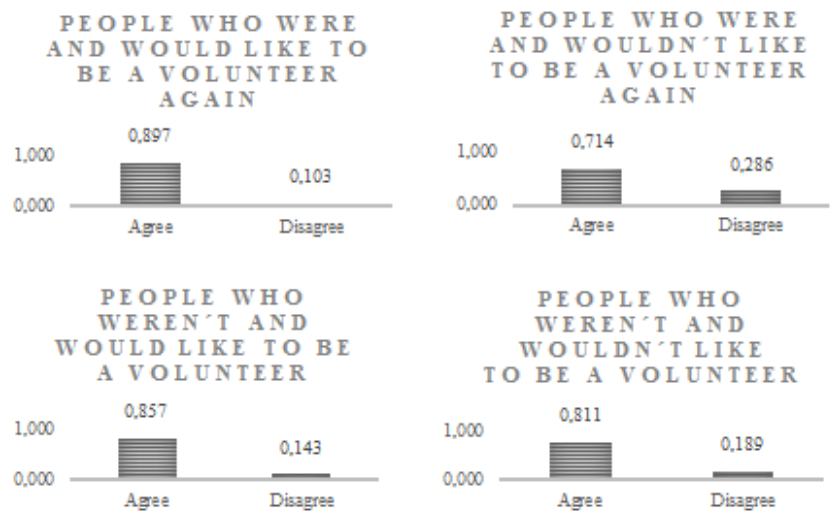

Fig. 9. What I want to do as a volunteer are my hobbies

Fig. 9 shows percentage answer of respondents who agree or disagree with the sentence: What I want to do as a volunteer are my hobbies. There can exist distortion in those who do not want to be volunteers. Answers of groups are still similar. Fig. 9 is the author research.

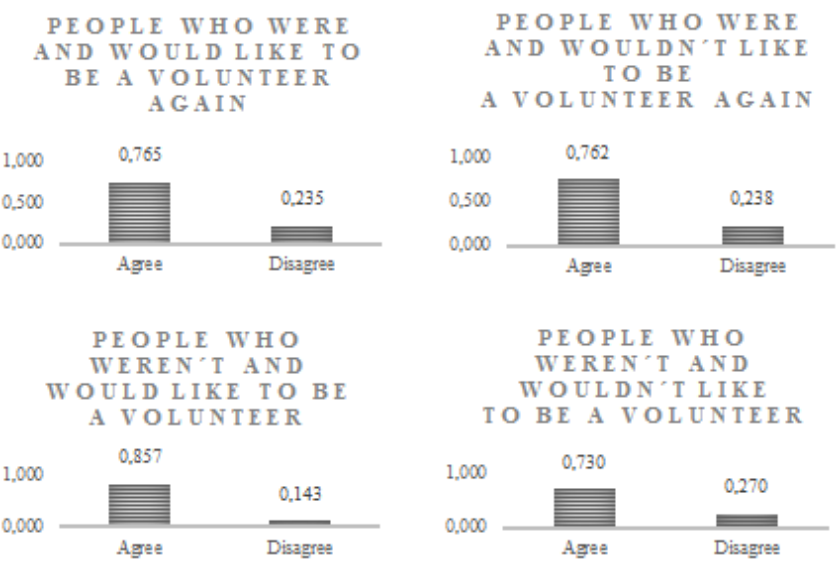

Fig. 10. I expect some benefit for myself from the volunteer project

Fig. 10 shows percentage answer of respondents who agree or disagree with the sentence: I expect some benefit for myself from the volunteer project. There is need selfreflection for the answers. Percentage of groups are similar. 
It is rather surprising that someone would like to participate in volunteer projects whether they would feel disadvantaged. There the answer could meant rather with an altruistic connection. Fig. 10 is the author research.

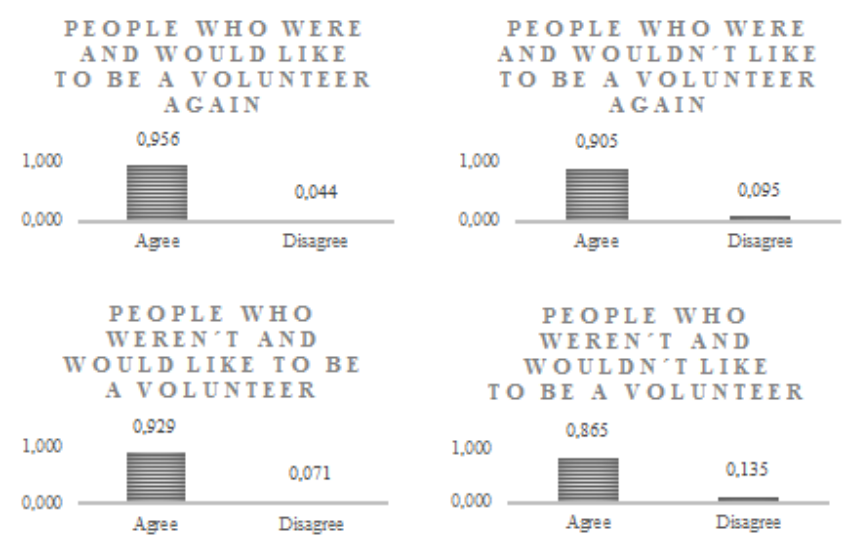

Fig. 11. I want to receive feedback from the people I work with

Fig. 11 shows percentage answer of respondents who agree or disagree with the sentence: I want to receive feedback from the people I work with. There exist high percentage of respondents who agree. Respondents are students who are taking feedback at school. There can exist connection between understanding that feedback is way how to self-develop. Fig. 11 is the author research.

\section{RESULT OF RESEARCH}

Chi-squared $(\chi 2)$ test was used for testing the hypothesis: "People who would like to be a volunteer have different approach to the self-development than people who would not like to be."

The input data are shown in figures up for above four mentioned categories of respondents. The test is performed at a significance level of $5 \%$. The value of $\chi 2$ is 268,0979 and with 70 degrees of freedom, the critical $\chi 2$ value is 90,531 . It means that the dependence between quantities was confirm. Therefore, the hypothesis, that people who would like to be a volunteer have different approach to the self-development than people who would not like to be.

\section{CONCLUSION}

People who would like to be a volunteer have different approach to the self-development than people who would not like to be. Even though the differences of values these research groups are very small, the dependence was confirmed. This research did not refuse statement of Gerdeman, Russell \& Worden [15], Thompson and Russell [16] who said that volunteering is way how to make a practices. Practices is opportunity how to self-develope. Baruch, May \& Yu, D. [36] state that a rapture for volunteering depends on age, personal experiences, innate assumptions [37]. This research reflects experiences with thinking about wanting of future self-planning with using self-reflecting to answer questions which were validated in smaller group and were discussed with experts.

As a discussion of this topic, it would be appropriate to extend the sample of respondents, results cannot be generalized due to sample constraints and different groups sizes too. There exist the other options how to extend this research. If it will be included aspects or factors like an age, a gender, a repetition of research, it could lead to other interesting results. It is possilbe to suppose that the peronality types for example MBTI test also influence research results [38]. In this research, the theoretical thinking of respondents in specific time was observed. These aspects could lead the research to interesting results.

\section{REFERENCES}

[1] Lourens, G. M., \& Daniels-Felix, D. K. "Hospital volunteerism as human resource solution: Motivation for both volunteers and the public health sector," SA Journal of Human Resource Management, 2017.

[2] Germain, A., Nolan, K., Doyle, R., Mason, S., Gambles, M., Chen, H., ... Ellershaw, J. "The use of reflective diaries in end of life training programmes: a study exploring the impact of self-reflection on the participants in a volunteer training programme," BMC Palliative Care, 2016.

[3] Alderman, M. K. "Motivation for achievement: Possibilities for teaching and learning," Routledge, 2013.

[4] Vallerand, R. J. "Toward a hierarchical model of intrinsic and extrinsic motivation." Advances in Experimental Social Psychology, 1997.

[5] Faye, C., \& Sharpe, D. "Academic motivation in university: The role of basic psychological needs and identity formation," Canadian Journal of Behavioral Science/Revue Canadienne Des Sciences Du Comportement, 2008.

[6] Ryan, R. M., \& Deci, E. L. "Intrinsic and extrinsic motivations: Classic definitions and new directions," Contemporary Educational Psychology, 2000.

[7] Maslow, A. H. "Toward a psychology of being," Simon and Schuster, 2013.

[8] Suyono, J., \& Mudjanarko, S. W. "Employee Abraham Maslow Theory,“ Journal of Education, Teaching and Learning, 2017.

[9] Frankl, V. E. "Man's search for meaning," Simon and Schuster, 1985.

[10] Fisher, E. "Motivation and Leadership in Social Work Management: A Review of Theories and Related Studies," Administration in Social Work, 2009.

[11] Weinbach, R.W. "Social worker manager: A practical guide to success," Boston: Allyn and Bacon, 1998.

[12] Elrod, L. M. M. Volunteering. Salem Press Encyclopedia, 2019.

[13] Kost, R. G., Lee, L. M., Yessis, J., Coller, B. S., \& Henderson, D. K. "Assessing Research Participants' Perceptions of their Clinical Research Experiences," Clinical and Translational Science, 2011.

[14] Duguid, F., K. Mündel, and D. Schugurensky. "Volunteer Work, Informal Learning and Social Action,“ Rotterdam: Sense Publishers, 2013.

[15] Gerdeman, R. D., Russell, A. A., \& Worden, K. J. Web-based student writing and reviewing in a large biology lecture course. Journal of College Science Teaching, 2007.

[16] Thompson, R., \& Russell, L. "Trainee teachers in unpaid teaching posts: volunteering, risk and vulnerability,“ Journal of Vocational Education \& Training, 2017.

[17] Simmons, R. and R. Thompson. "Aiming higher: how will universities respond to changes in initial teacher training for the postcompulsory sector in England? " Journal of Further and Higher Education, 2007.

[18] Bauman, Z. "Freedom,“ Milton Keynes: Open University Press. 1988.

[19] Beck, U. "Risk Society: Towards a new modernity," London: Sage, 1992.

[20] Giddens, A. "Modernity and Self-Identity: Self and society in the late modern age," Cambridge: Polity, 1991.

[21] Jilkova, P. "Brands we Love or Know on the Czech Financial Market." In: Marketing Identity: Brands we love - part II.. Trnava: University of SS. Cyril and Methodus, 2016. p. $118-126$.

[22] Reynolds, J. A., Thaiss, C., Katkin, W., \& Thompson, R. J. "Writingto-learn in undergraduate science education: A community-based, conceptually driven approach, “CBE - Life Sciences Education, 2012.

[23] Quitadamo, I. J., \& Kurtz, M. J. "Learning to improve: Using writing to increase critical thinking performance in general education biology,"CBE—Life Sciences Education, 2007. 
[31] Rosenbaum, M. E., Lobas, J., Ferguson, K. "Using reflection activities to enhance teaching about end-of-life care,“ J Palliat Med. 2005.

for computer-assisted learning of biological research competencies." Bio-chemistry and Molecular Biology Education, 2010.

[25] Bereiter, C., \& Scardamalia, M. "The psychology of written composition,“ Mahwah, NJ: Erlbaum, 1987.

[26] Carini, R. M., Kuh, G. D., Klein, S. P. "Student engagement andstudent learning: testing the linkages," Res High Educ, 2006.

[27] Cui, G., Yao, M., Zhang, X., Guo, Y., Li, H., \& Yao, X. "The effects of initial participation motivations on learning engagement in transition training for future general practitioners in rural China: perceived deterrents as mediator," Medical Education Online, 2016.

[28] Chris, D. C. "Immersive interfaces for engagement and learning," Science, 2009.

[29] Miller, R. B., Greene, B. A., Montalvo, G. P., Ravindran, B., Nichols, J. D. "Engagement in academic work: the role of learning goals, future consequences, pleasing others, and perceived ability," Contemp Educ Psychol, 1996.

[30] Schaufeli, W. B., Martinez, I. M., Pinto, A. M., Salanova M., Bakker, A. B. "Burnout and engagement in university students: a crossnational study," J Cross Cult Psychol, 2002.

[32] Boud D, Keogh R, Walker D. "Reflection: Turning experience into learning," London: Kogan Page, 1985.

[33] Sandars, J. E. "The use of reflection in medical education," Med Teach, 2009.

[34] Ghaye, T. Reflection: Principles and practice for healthcare professionals 2nd edition. London: Mark Allen Publishing Ltd; 2010

[35] Burrows, D. E.. "The nurse teacher's role in the promotion of reflective practice," Nurse Educ Today, 1995.

[36] Baruch, A., May, A., \& Yu, D. "The motivations, enablers and barriers for voluntary participation in an online crowdsourcing platform,"Computers in Human Behaviour, 2016.

[37] Zarubova, L. "Is volunteering a way how students get the practice?" IFRS: Global Rules \& Local Use, 2019.

[38] Zarubova, L. "Does a difference in the motivation of volunteers and other people exist?" International Days of Statistics and Economics, 2019 . 